Journal of the Egyptian Society of Parasitology, Vol.43, No.2, August 2013 J. Egypt. Soc. Parasitol., 43(2), 2013: 425 - 427

\title{
MICROFILARIA IN BREAST ASPIRATION - AN UNCOMMON FINDING
}

\section{By}

RAJIB KUMAR MONDAL*, RUDRANARAYAN RAY, HENA KAWSAR, SADAKKAS ALI AND KUMAR TAPAN GHOSH

Department of Pathology, Vill-Barjora, Schooldanga, BSMC, Bankura, West Bengal, India

*Correspondence: Vill-Barjora, Schooldanga, Barjora-722202, Bankura, West Bengal India Email-rajibkmondal@yahoo.co.in,Mobileno-94343654628

\section{Abstract}

Filariasis is a major public health problem in many tropics and subtropics of Africa, Western Pacific and parts of the Americas, affecting over 83 countries. It is also a public health problem in India. A large majority of the cases found in India are attributed to infection by Wuchereria bancrofti which mainly affects the lymph nodes and the lymphatic channels. Breast is an unusual site for filariasis. In the present case report the patient presented with a gradually increasing breast lump, clinically diagnosed as fibroadenoma.

Key words: India, Breast, Wuchereria bancrofti, (FNAC).

\section{Introduction}

Tropical diseases are always been endemic in the region of Asian and African countries. Filariasis affects the lymphatic system with a predilection for lower limbs, retroperitoneal tissues, spermatic cord, and epididymis. It is caused by two closely related nematodes and transmitted by Culex mosquitoes (Kaur Rupinder et al, 2009). Filaria can affect other sites rarely. Though single or small number of cases on microfilariae at various sites as lymph node, thyroid, bone marrow, bronchial aspirates, nipple secretion, pleural and pericardial fluid, ovarian cyst fluid and cervical-vaginal smear have been reported, breast is another site from which microfilaria has been isolated. It is estimated that approximately 600 million people are living in areas endemic for lymphatic filariasis in Southeast Asia Region. There are approximately 60 million people infected in the region and approximately 31 million people have the clinical manifestation of this disease (Chowdhary et al, 2008).

\section{Case Report}

A $34 \mathrm{yr}$ old female was presented in the surgical OPD with a gradually increasing lump in the right breast. On examination a $(2.5 \times 2) \mathrm{cm}$ mass was palpable in the upper outer quadrant of right breast. The overlying skin, nipple and areola were unaffected. Axillary lymph nodes were not palpable. Routine hematological investigations were normal.

(FNAC) was done from the lump in the right breast. Smears were cellular and showed numerous polymorphs, 
eosinophils, and foamy histiocytes with a necrotic background. Also seen amidst them were many microfilariae of $W$. bancrofti which were rounded anteriorly and tapering posteriorly. The microfilariae had a clear space free of nuclei at the caudal end. No ductal or malignant cells were identified. A cytological diagnosis of filariasis of the right breast was made.

\section{Discussion}

Filariasis is a global problem (AbdelHamid et al, 2011), particularly in Ar$a b$ countries where the vector is widely distributed (William et al, 2009; Osta et al, 2012; El-Bahnasawy et al, 2013). There are eight identified species of filarial parasite among them only three (W. bancrofti, B. malayi and Brugia timori) are known to cause lymphatic filariasis (Park, 2013). In India microfilariae bancrofti and microfilariae mala$y i$ are the commonly prevalent ones (Chatterjee, 2009). The diagnosis is done on the basis of morphology of the microfilaria. Microfilariae of $B$. malayi are smaller than those of $W$. bancrofti, possess secondary kinks instead of a smooth curve, and unlike the latter, the tip is not free of the nuclei (Park, 2013). The life cycle of the filarial worms (bancroftian and brugian filariasis) can be divided into the mosquito phase and the human phase.

Infective larvae are transmitted by infected biting mosquitoes during a blood meal. The larvae migrate to lymphatic vessels and lymph nodes, where they develop into microfilariae-to adults. The adults dwell in lymphatic vessels and lymph nodes where they can live for several years. The female worms produce microfilariae which circulate in the blood. The microfilariae infect biting mosquitoes. Inside the mosquito, the microfilariae develop in 1 to 2 weeks into infective filariform (third-stage) larvae, during a subsequent blood meal by the mosquito; the larvae infect the vertebrate host. They migrate to the lymphatic vessels and lymph nodes of the human host, where they develop into adults (Bahgat et al, 2011). The clinical manifestations of lymphatic filariasis may range from the asymptomatic microfilariasis to hydrocele, lymphangitis, lymphadenitis with high-grade fever (filarial fever), and lymphatic obstruction (Sodhani et al, 1993). In this case patient was clinically diagnosed as fibro-adenoma breast. The subsequent extensive search for microfilaria in blood did not yield any result (Sivakumar et al, 2007). In the present case, no skin changes in the breast lesion but in other studies skin changes was seen due to lymphatic obstruction (Bhardwaj et al, 2007). The $W$. bancrofti microfilariae were detected in different lesions, but no case was documented from breast as it's unusual to find in breast smears (Walter et al, 1983). Filariasis can be cured with administration of diethyl carbamazine (DEC), but the treatment of chronic lymphatic obstruction is difficult (Lahariya and Tomar, 2011)

\section{Conclusion}

No doubt filariasis is one of the main tops of WHO interest. Filariasis of the breast is an uncommon condition and need a high index of suspicion and careful screen of FNA smears especial- 
ly in asymptomatic patients belonging to endemic zones, so as not to miss this incidental finding especially in patients from endemic areas.

In the context of filariasis elimination programme, use of antigen detection in the diagnosis of filariasis, particularly in young children is important as the treatment at an earlier age may prevent subsequent development of the clinical disease.

\section{References}

Abdel-Hamid, YM, Soliman, MI, Kenawy, MA, 2011: Geographical distribution and relative abundance of culicine mosquitoes in relation to transmission of lymphatic filariasis in El Menoufia Governorate, Egypt. J. Egypt. Soc. Parasitol. 41, 1:109-18.

Bahgat, MM, Saad, AH, El-Shahawi, GA, Gad, AM, Ramzy, RM, et al, 2011: Cross-reaction of antigen preparations from adult and larval stages of the parasite Setaria equina with sera from infected humans with Wuchereria bancrofti. East. Mediterr. Hlth. J. 17, 8: 679-86.

Bhardwaj, S, Mahajan, D, Attri, M R, 2007: Filariasis of the breast. J. K Sci. 9:98-9

Chatterjee, KD, 2009: Phylum Nemathelminthes. In: Parasitology. $13^{\text {th }}$ ed. New Delhi, CBS Publishers.

Chowdhary, M, Langer, S, Agarwal, M, Agarwal, C, 2008: Microfilaria in thyroid gland nodule. Indian J. Pathol. Microbiol. 51, 1:94-6.

El-Bahnasawy, MM, Khater, MMK h, Morsy, TA, 2013: The mosquito borne West Nile virus infection: Is it threating to Egypt or a neglected endemic disease? J. Egypt. Soc. Parasitol. 43, 1:87-102.

Kaur Rupinder, Kandathil Joseph Phillip, Kanwal Masih, Rajeev Kapoor, Cecil Johnny, 2009: Filariasis of the breast mimicking inflammatory carcinoma. Lab. Med. 40, 11:683-5.

Lahariya, C, Tomar, SS, 2011: How endemic countries can accelerate lymphatic filariasis elimination? An analytical review to identify strategic, and programmatic interventions. J. Vector Borne Dis. 48, 1:1-6.

Mikhail, MW, Al-Bursheed, KhM, AbdEl-Halim, AS, Morsy, T A, 2009: Studies on mosquito borne diseases in Egypt and Qatar. J. Egypt. Soc. Parasitol. 39, 3:745-56

Osta, MA, Rizk, ZJ, Labbé, P, Weill, M, Knio, K, 2012: Insecticide resistance to organophosphates in Culex pipiens complex from Lebanon. Parasit Vectors 5:132.

Park, K, 2013: Epidemiology of communicable disease. In: Textbook of Preventive and Social Medicine, $22^{\text {st }}$ ed.; Jabalpur, Banarsidas Bhanot Publishers.

Sivakumar, S. Sivakumar, S, 2007: Role of fine needle aspiration cytology in detection of microfilariae: report of 2 cases. Acta Cytol. 51, 5:803-6.

Sodhani, P, Murty, DA, Pant, CS, 1993: Microfilaria in a fine needle aspirate from a breast lump: A case report. Cytopathology 4:59-62.

Walter, A, Hemlatha, K, Cariappa, A, 1983: Microfilariae of Wuchereria bancrofti in cytological smear. Acta Cytol. 4:432-6. 